\title{
Effects of TAP-144-SR, A Sustained-Release Formulation of a Potent GnRH Agonist, on Experimental Endometriosis in the Rat
}

\author{
Katsuichi SUDO, Kunio SHIOTA, Tsuneo MASAKI and Takeshi FUJITA \\ Biology Research Laboratories, Research and Development Division, \\ Takeda Chemical Industries, Ltd., Osaka 532, Japan
}

\begin{abstract}
A new, simple experimental endometriosis model was established by auto-transplanting endometrial tissue fragments beneath kidney capsules in female rats. The transplanted endometrial tissue grew well, forming a fluid-filled cyst, which reached maximal size 2 to 3 weeks after transplantation. The growth and maintenance of the transplants was dependent on the ovary: ovariectomy induced regression of well grown transplants. The therapeutic effects of TAP-144-SR (biodegradable microcapsules of copoly (DL-lactic/glycolic acid) copolymer containing a potent GnRH agonist, TAP-144 (D-Leu ${ }^{6}-\left[\right.$ des-Gly $\left.{ }^{10}-\mathrm{NH}_{2}\right]-\mathrm{GnRH}$ ethylamide, leuprolide acetate) were studied with this rat endometriosis model. A single sc injection of TAP-144-SR (corresponding to 1, 10 or 100 $\mu \mathrm{g} / \mathrm{kg} /$ day of TAP-144), suppressed the growth of the transplanted endometrial tissues and uterine weight in a dose-dependent manner. At $100 \mu \mathrm{g} / \mathrm{kg} /$ day, the suppressive effect was more marked in rats given TAP-144-SR than in those given TAP-144 solution. The extent of suppression was comparable to that caused by ovariectomy. Serum and pituitary concentrations of LH and FSH were also reduced more markedly by the administration of TAP-144-SR than by TAP-144 solution. From these results, the present endometriosis model was found to be useful for the evaluation of compounds with potential therapeutic activity. The sustained-release formulation of TAP-144 seems to be beneficial over its solution in terms of both convenience and efficiency for therapy of patients with endometriosis.
\end{abstract}

(Endocrinol Japon 38: 39-45, 1991)

ENDOMETRIOSIS is one of the most common diseases among women in their thirties and forties. Animal models of endometriosis have been reported with rabbits [1,2], monkeys [3] and rats [4]. For evaluation of the therapeutic potential of GnRH agonists, an animal model of endometriosis with rats is most suitable because of the high sensitivity of these animals to $\mathrm{GnRH}$ agonists $[5,6]$ and practical considerations. However, we experienced problems with the procedure in explanting endometrial tissue into the peritoneal cavity according to the method of Jones [4]. Inconsistent growth of the transplants and attachment of fat

Received: July 31, 1990

Accepted: December 21, 1990

Correspondence to: Dr. Katsuichi SUDO, 2-17-85 Jusohonmachi, Yodogawa-ku, Osaka 532, Japan

Part of this paper was presented at the Annual Meeting of the Endocrine Society of Japan, Kyoto, 1987. tissue to them resulted in a low yield of usable animals. We then tried auto-transplanting endometrial tissue fragments under the kidney capsules of female rats and succeeded in establishing a simple endometriosis model.

Potent GnRH agonists have been reported to downregulate the gonadal functions in chronic treatment of pharmacological doses and this paradoxical effect has been clinically utilized in treating a variety of hormonally responsive clinical disorders [7, 8]. The paradoxical effects of GnRH agonists are thought to be mainly due to desensitization of the pituitary and gonads [9]. Recently, biodegradable microcapsules of copoly (DLlactic/glycolic acid) (PLGA) copolymer containing a potent GnRH agonist, TAP-144 (leuprolide acetate, (D-Leu ${ }^{6}$-[des-Gly $\left.{ }^{10}-\mathrm{NH}_{2}\right]$-GnRH ethylamide acetate; $[10,11]$ were developed with a view to maintaining a constant release for 1 month [12, 
13]. Administration of TAP-144-SR has been shown to decrease the testosterone concentration and prostate weight in male rats and dogs [14] and to decrease serum estradiol in female rats $[13,15]$. Besides the advantage of reducing the frequency of injections, maintaining constant TAP-144 levels in serum by TAP-144-SR administration may affect the potency of the paradoxical effects of the GnRH agonist.

In the present study, the therapeutic effects of TAP-144-SR were examined by means of our new simple endometriosis model in rats. The therapeutic effectiveness of TAP-144-SR was compared with that of TAP-144 adminstered as a solution.

\section{Materials and Methods}

Animals and treatment

TAP-144-SR was prepared by suspending TAP144-containing microcapsules of PLGA copolymer in $2.5 \mathrm{ml} / \mathrm{kg}$ of suspension vehicle. The concentration of TAP-144 in the microcapsules was $8 \%$. The method for preparing TAP-144-containing microcapsules has been described elsewhere [12]. The daily equivalent dose was calculated by dividing the injected dose by 30 . The TAP-144 solution was made up in $1 \mathrm{ml} / \mathrm{kg}$ of saline. Rats were injected sc with either TAP-144 solution or TAP-144-SR.

\section{Preparation of endometriosis in rats}

Experimental endometriosis in rats was prepared as follows. Female rats of Sprague-Dawley strain (Charles River Japan, Inc.) aged 9 weeks were anesthetized with ether, and an abdominal incision was made. The uterine blood vessels were ligated and about a $15-\mathrm{mm}$ segment of the left uterine horn was excised. The myometrium was separated from the endometrium, and a $5 \times 5 \mathrm{~mm}$ endometrial fragment was cut off. Histological examination confirmed that the myometrium was largely separated from the endometrial tissue fragment. The endometrial tissue fragment was inserted beneath the kidney capsule of each rat through an incision made in it. Two weeks after the implantation, the animals were laparotomized, and the growth of the implanted endometrial tissues was determined. Animals exhibiting good growth of the implants were used for experiments. Ovariectomy in rats was performed on the 1st day of the treatment. Rats in the control group were given the suspension vehicle. Three weeks after the start of the treatment (one day after the last injection of TAP-144 solution or 3 weeks after a single injection of TAP-144-SR), growth of the endometrial transplants was determined upon laparotomy under ether anesthesia. The weight of ovaries and hemi-uteri (right side, without fluid) was also determined after withdrawal of blood from the abdominal aorta.

The extent of growth of endometrial transplants was ranked from A to D according to size, as shown below. For statistical analysis, transplants in each category were given scores, as shown in parentheses.

A: excellent growth with fluid ( $\geqq 2 \mathrm{~mm}$, in height, score 3)

B: moderate growth with fluid $(0.4 \mathrm{~mm} \sim 2 \mathrm{~mm}$ in height, score 2)

C: minimal growth without fluid $(0 \mathrm{~mm} \sim 0.4 \mathrm{~mm}$ in height, score 1)

D: completely regressed without fluid $(=0 \mathrm{~mm}$ in height, score 0 )

\section{Radioimmunoassay}

Serum concentrations of $\mathrm{LH}$ and $\mathrm{FSH}$ were determined by a double antibody radioimmunoassay with NIADDK rat RIA kits [16]. Purified LH (NIADDK-rat LH-I-7) and FSH (NIAMDD-rat FSH-I-4) were labeled with ${ }^{125} \mathrm{I}\left({ }^{125} \mathrm{I}-\mathrm{NaI}\right.$, New England Nuclear, Du Pont) according to the chloramine-T method of Greenwood et al. [17]. Serum levels of LH and FSH were expressed in terms of NIAMDD-rat LH-RP-1 and NIAMDDrat FSH-RP-1, respectively.

\section{Statistical analysis}

Statistical analysis was carried out by analysis of variance followed by Dunnett's test unless otherwise described. Statistical analysis was also carried out by Student's $t$-test to compare the efficacy of the two dosage formulations, TAP-144 solution and TAP-144-SR, at the respective daily doses.

\section{Results}

\section{Growth of endometrial tissue fragments}

In control rats, transplanted endometrial tissue fragments exhibited good growth, each forming a fluid-filled cyst (Fig. la) 3 weeks after the start of the experiment. Ovariectomy induced complete inhibition of transplant growth. Upon treatment with either TAP-144 solution daily or once with 

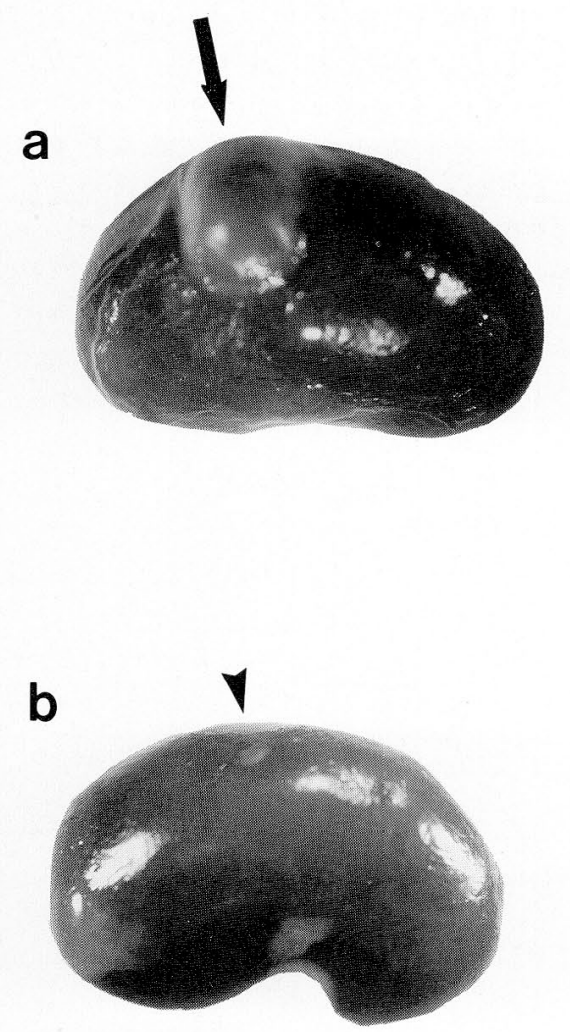

Fig. 1. Photographs of auto-transplanted endometrial tissues beneath kidney capsules. Two weeks after transplantation, rats were treated once with TAP144-SR, and killed 3 weeks after TAP-144-SRtreatment. a: Control; b: TAP-144-SR-treated (100 $\mu / \mathrm{kg} /$ day equivalent of TAP-144) The arrow indicates a fluid-filled transplant, and the arrowhead indicates a regressed transplant.

TAP-144-SR, growth of the transplants was suppressed in a dose-dependent manner. Figure $1 b$ shows a representative transplant in a rat treated with the highest dose (corresponding to 100 $\mu \mathrm{g} / \mathrm{kg} /$ day of TAP-144) of TAP-144-SR, exhibiting severe regression. The severely regressed transplants were macroscopically similar to those in ovariectomized rats.

The growth of transplanted endometrial tissue fragments is summarized in Fig. 2. When the activity of the two dosage forms of TAP-144 was compared, the TAP-144 solution was found to be slightly more effective at the lowest dose (1 $\mu \mathrm{g} / \mathrm{kg} /$ day equivalent of TAP-144), and TAP-144SR was slightly more effective at the highest dose $(100 \mu \mathrm{g} / \mathrm{kg} /$ day equivalent of TAP-144). The extent of the regression caused by the highest dose of TAP-144-SR was comparable to that caused by ovariectomy.

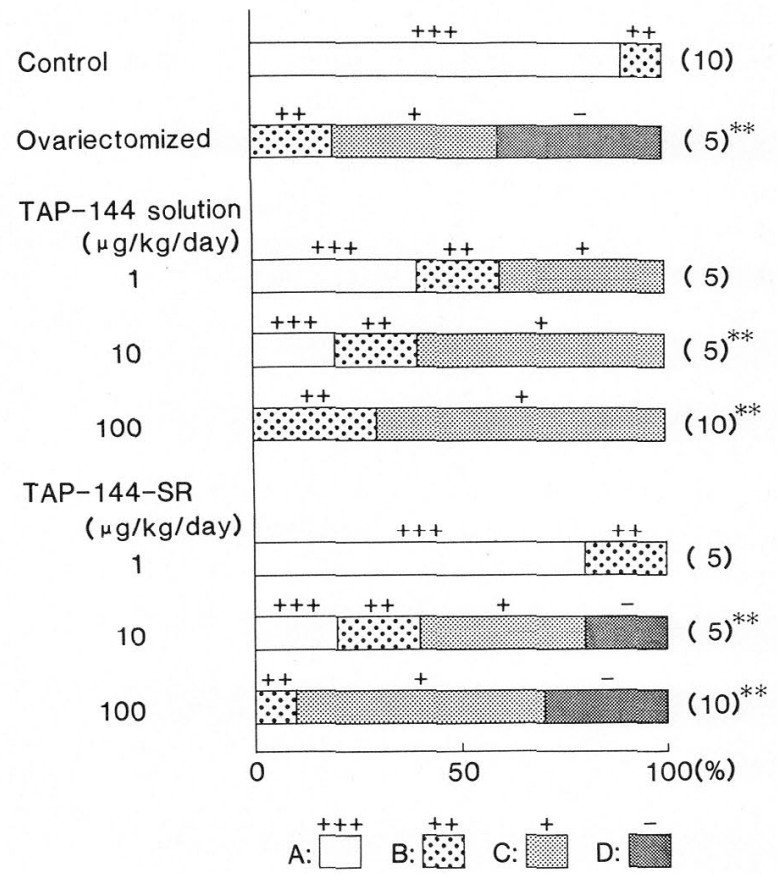

Fig. 2. Effects of TAP-144 solution and TAP-144-SR on growth of transplanted endometrial tissue fragments in rats. Two weeks after transplantation, rats were ovariectomized or treated with TAP-144 (either daily as a solution or once as a sustainedrelease formulation), and killed 3 weeks after the initiation of treatment.

A: excellent growth with fluid ( $\mathrm{m}$ : $\geqq 2 \mathrm{~mm}$, in height, score 3)

B : moderatc growth with fluid (H: $0.4 \mathrm{~mm} \sim 2$ $\mathrm{mm}$ in height, score 2)

C: minimal growth without fluid $(+: 0 \mathrm{~mm} \sim 0.4$ $\mathrm{mm}$ in height, score 1)

$\mathrm{D}$ : completely regressed without fluid $(-:=0$ $\mathrm{mm}$ in height, score 0 )

The numbers in the parentheses are the numbers of rats of each group.

**: $\mathrm{P}<0.01$ (significantly different from the control by analysis of variance followed by Dunnett's test). Doses of TAP-144-SR are expressed as corresponding daily doses of TAP-144.

Uterine and ovarian weight

The administration of TAP-144, as either daily injections of TAP-144 solution or a single injection of TAP-144-SR, produced dose-dependent suppression of hemi-uterine weight (Fig. 3). At the lowest dose ( $1 \mu \mathrm{g} / \mathrm{kg} /$ day equivalent of TAP-144), a slightly more marked reduction in hemi-uterine weight was observed in TAP-144 solution-treated rats, while a more marked reduction was observed in TAP-144-SR-treated rats at the highest dose $(\mathrm{P}<0.01, t$-test $)$. The difference was statistically 


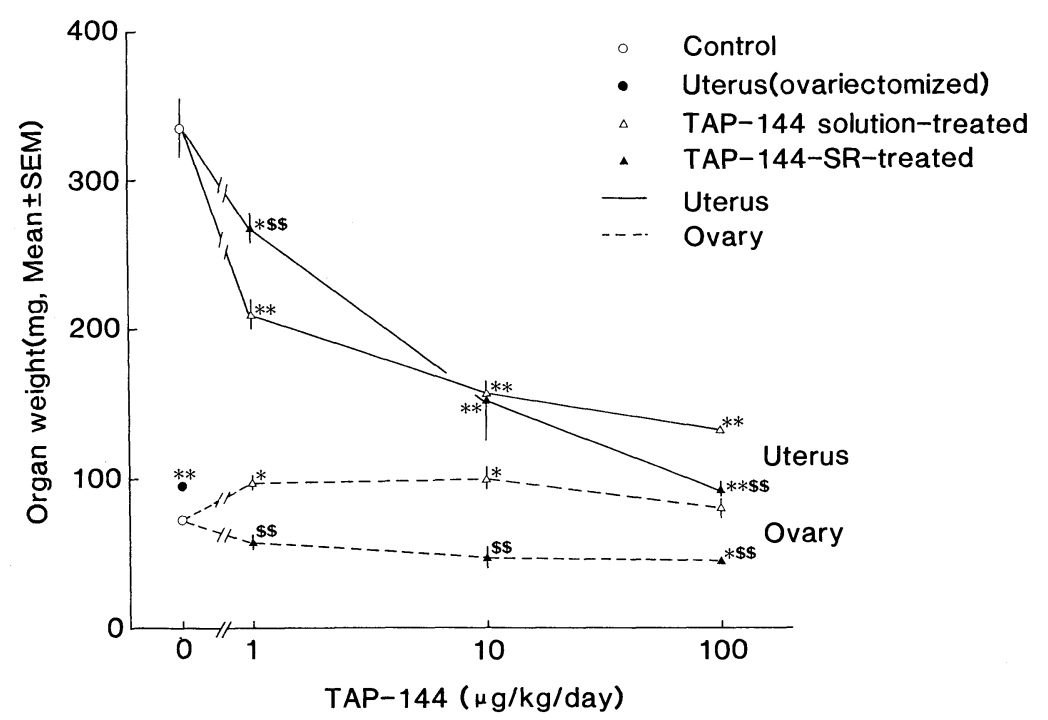

Fig. 3. Effects of TAP-144 solution and TAP-144-SR on uterine and ovarian weight of rats. Organ weight was determined 3 weeks after the start of treatment ( 5 weeks after transplantation).

Mean \pm SEM, $n=4-10$

$*: \mathrm{P}<0.05$, **: $\mathrm{P}<0.01$ (significantly different from the control by analysis of variance followed by Dunnett's test). $\$ \$: \mathrm{P}<0.01$ (significantly different from TAP-144 solution-treated rats with the same daily dose by $t$-test). Doses for TAP-144-SR are expressed as corresponding daily doses of TAP-144.

Table 1. Effects of TAP-144 solution and TAP-144-SR on serum and pituitary concentrations of LH and FSH in rats Gonadotropin concentrations were determined 3 weeks after initiation of treatment (5 weeks after transplantation).

\begin{tabular}{lcccc}
\hline & \multicolumn{2}{c}{ Serum } & \multicolumn{2}{c}{ Pituitary } \\
\cline { 2 - 5 } & $\begin{array}{c}\mathrm{LH} \\
(\mathrm{ng} / \mathrm{m} l)\end{array}$ & $\begin{array}{c}\text { FSH } \\
(\mathrm{ng} / \mathrm{m} l)\end{array}$ & $\begin{array}{c}\text { LH } \\
(\mu \mathrm{g} / \mathrm{mg} \text { pituitary })\end{array}$ & $\begin{array}{c}\text { FSH } \\
(\mu \mathrm{g} / \mathrm{mg} \text { pituitary })\end{array}$ \\
\hline Control & $15.9 \pm 1.6$ & $179.2 \pm 51.2$ & $20.82 \pm 3.03$ & $1.17 \pm 0.07$ \\
$\begin{array}{l}\text { Ovariectomized } \\
\text { TAP-144 solution } \\
\quad(0.1 \mathrm{mg} / \mathrm{kg} / \text { day })\end{array}$ & $222.2 \pm 26.3^{* *}$ & $1184.8 \pm 79.6^{* *}$ & $79.53 \pm 9.27^{* *}$ & $10.07 \pm 1.52^{* *}$ \\
$\begin{array}{c}\text { TAP-144-SR } \\
(0.1 \mathrm{mg} / \mathrm{kg} / \text { day })\end{array}$ & $39.9 \pm 6.8^{* *}$ & $428.2 \pm 61.5^{*}$ & $11.10 \pm 0.54^{*}$ & $1.42 \pm 0.18$ \\
\hline
\end{tabular}

Mean \pm SEM $(n=5)$

*: $\mathrm{P}<0.05$; **: $\mathrm{P}<0.01$ (significantly different from the control by analysis of variance followed by Dunnett's test) $\$ \$$ : $\mathrm{P}<0.01$ (significantly different from TAP-144 solution-treated rats with the same daily dose by $t$-test)

The dose for TAP-144-SR is expressed as corresponding daily dose of TAP-144.

significant. Hemi-uterine weight reduciton of rats treated with the highest dose of TAP-144-SR was comparable to that of ovariectomized rats. Ovarian weight was increased slightly by the administration of TAP-144 solution, but slightly decreased by the administration of TAP-144-SR. The difference in ovarian weight among the groups of rats treated with either of the 2 dosage forms was statistically significant when comparison was made based on the same daily doses $(\mathrm{P}<0.01, t$-test $)$.

\section{Gonadotropin concentrations}

Ovariectomy markedly increased the serum and pituitary concentrations of $\mathrm{LH}$ and FSH (Table 1). Administration of the TAP-144 solution (100 $\mu \mathrm{g} / \mathrm{kg} /$ day) significantly increased the serum con- 
centrations of $\mathrm{LH}$ and $\mathrm{FSH}$, and decreased the pituitary concentrations of FSH. Administration of the same dose of TAP-144-SR, however, significantly decreased the serum concentration of FSH, and the pituitary concentrations of LH and FSH. The difference in the effects of the 2 dosage forms was statistically significant $(\mathrm{P}<0.01, t$-test $)$.

\section{Discussion}

Growth of transplanted endometrial tissue fragments beneath kidney capsules was highly dependent on the ovary, and the transplanted tissues reached maximal size about 2 weeks after transplantation. The dependency on the ovary and the time schedule of preparation and observation of endometrial tissue transplants were the same as for the endometriosis model of Jones [4]. In our present rat endometriosis model, however, timeconsuming suturing was not necessary, the transplanted endometrial fragments grew well, and they remained free of attached adipose tissue. Histological study confirmed the formation of a large cyst composed of epithelium in the control, and a small cyst with flattened and pyknotic epithelium in ovariectomized rats [18]. The marked decrease in the size of the transplants in TAP-144-SR-treated rats observed in this study coincides with a histological study showing regression of the cysts in these rats [18]. The decrease in the size of the transplants is thought to be caused by suppression of the serum estradiol level by TAP-144-SR treatment [13, 15]. This model was found to be simple but useful for the evaluation of test compounds having therapeutic potential for endometriosis.

Subcutaneous administration of TAP-144, either as a solution or as a sustained-releasing formulation, dose-dependently suppressed the growth of the auto-transplanted endometrial tissues and hemi-uterine weight. At the highest daily dose $(100 \mu \mathrm{g} / \mathrm{kg} /$ day equivalent of TAP-144) of TAP-144-SR, but not of TAP-144 solution, the extent of suppression of endometrial tissue growth and reduction of hemi-uterine weight were comparable to those caused by ovariectomy. The results are in good accordance with those reported in another endometriosis model [13]. Although the difference in transplant growth was not statistically significant, other markers such as pituitary and serum gonadotropins, and uterine weight exhibited a statistically significant difference. Thus, it is likely that the efficacy of the 2 dosage forms in suppressing transplant growth also differs without statistical significance due to great variation from animal to animal. These results indicate that at the highest dose, the sustainedrelease formulation of TAP-144 is more effective than TAP-144 solution in suppressing ovarian hormone-dependent tissue growth. TAP-144-SR is also more effective than TAP-144 solution in suppressing testicular hormone-dependent accessory sex organ weight in male rats [19]. The reason why TAP-144-SR is more efficient than TAP-144 solution at the highest dose, and the reverse is true at the lowest dose may be explained as follows. The lowest dose of TAP-144-SR may give a constant, but an insufficient serum concentration of TAP-144 to exhibit pharmacological actions. In contrast, TAP-144 solution can give a transient, but sufficient serum concentratin of TAP-144 to exhibit pharmacological actions. This is the reason why TAP-144 solution is more efficient than TAP-144-SR at the lowest dose. At the highest dose, maintaining a constant concentratin of TAP144 with TAP-144-SR may be more effective for desensitization, which requires long-term occupancy of target cells.

The effects of TAP-144 administration on the serum and pituitary concentrations of gonadotropins and ovarian weight for the two dosage formulations were different; administration of the solution increased the serum $\mathrm{LH}$ and FSH concentrations and ovarian weight, and decreased the pituitary LH concentration, whereas the administration of TAP-144-SR decreased the serum FSH, pituitary LH and FSH concentrations and ovarian weight. This discrepancy in the effects of the two dosage formulations on gonadotropin levels has also been observed in male rats [19]. Pituitary concentrations of $\mathrm{LH}$ and $\mathrm{FSH}$ are also lower in TAP-144-SR-treated than in TAP-144-solutiontreated male rats. Desensitization of the gonads is usually associated with high serum concentrations [9]. Although serum LH concentrations in TAP144-SR-treated rats are not higher than those in the control rats, the desensitization might have been induced by high serum concentrations of LH shortly after the TAP-144-SR treatment [15]. Additionally, the desensitization may continue as long as serum TAP-144 concentrations are maintained at levels sufficient to stimulate the pituitary. 
In fact, TAP-144-SR-treated rats produce very little testosterone upon hCG treatment [15]. Also, other factors such as a decrease in bioactive gonadotropins and/or continued direct inhibitory action on the gonads [5, 6, 9], may be involved in the paradoxical effects. The results of this study suggest that the effects of GnRH agonists on gonadotropins vary according to the dosage form, doses and duration of treatment; the relative importance of mechanisms through which desensitization is induced also varies according to these factors.

\section{Acknowledgements}

We appreciate the useful advice on statistical analysis by Mr. Chikuma Hamada, M. Sc. We thank Mr. Y. Yoshida and Miss Y. Akinaga for their technical support. We also wish to thank NIAMDD (NIH) for gifts of pituitary hormone assay kits.

\section{References}

1. Schenken RS, Asch RH (1980) Surgical induction of endometriosis in the rabbit: effects on fertility and concentrations of peritoneal fluid prostaglandins. Fertil Steril 34: 581-587.

2. Hahn DW, Carraher R, Foldesy R, McGuire JL (1983) The effect of danazol on surgically induced endometriotic implants in rabbits. Proc 65th Ann Mtg Endocrinol Soc, June 1983.

3. Dizerga GS, Barber DL, Hodgen GD (1980) Endometriosis: role of ovarian steroids in initiation, maintenance and suppression. Fertil Steril 33: 649-653.

4. Jones RC (1984). The effect of a luteinizing hormone releasing hormone (LRH) agonist (Wy40,972), levonorgestrel, danazol and ovariectomy on experimental endometriosis in the rat. Acta Endocrinol 106: 282-288.

5. Hsueh AJ, Jones PBC (1981) Extrapituitary actions of gonadotropin-releasing hormone. Endocrine Reviews 2: 437-461.

6. Cooke BA, Sullivan MHF (1985) The mechanism of LHRH agonist action in gonadal tissues. Molecular Cellular Endocrinol 41: 115-122.

7. Warner B, Worgul TJ, Drago J, Demers L, Dufau M, Max D, Santen J (1983) Effect of very high dose D-leucine ${ }^{6}$-gonadotropin-releasing hormone proethylamide on the hypothalamic-pituitary testicular axis in patients with prostatic cancer. J Clin Invest 71: 1842-1853.

8. Nicholson RI, Walker KJ, Turkes A, Turkes AO, Dyas J, Blamey RW, Campbell FC, Robinson MRG, Griffiths K (1984) Therapeutic significance and the mechanism of action of the LH-RH agonist ICI 118630 in the breast and prostate cancer. J Steroid Biochem 20: 129-135.

9. Bhasin S, Swerdloff RS (1986) Mechanism of gonadotropin-releasing hormone agonist action in the male. Endocrine Reviews 7: 106-114.

10. Fujino M, Fukuda T, Shinagawa S, Kobayashi S, Yamazaki I, Nakayama R, Seely JH, White WH, Rippel RH (1974) Synthetic analogs of luteinizing hormone-releasing hormone (LH-RH) substituted in position 6 and 10. Biochem Biophys Res Commun 60: 406-413.

11. Rippel RH, Johnson ES, White WF, Fujino M, Fukuda T, Kobayashi S (1975) Ovulation and gonadotropin-releasing activity of (D-Leu ${ }^{6}$, des$\mathrm{GlyNH}_{2}{ }^{10}$, Pro-ethylamide ${ }^{9}$ )-GnRH (38715). Proc Soc Exp Biol Med 148: 1193-1197.

12. Ogawa Y, Okada H, Yamamoto M, Shimamoto T (1988) In vivo release profiles of leuprolide acetate from microcapsules prepared with polylactic acids or copoly (lactic/glycolic) acids and in vivo degradation of these polymers. Chem Pharm Bull 36: 2576-2581.

13. Okada H, Heya T, Ogawa Y, Shimamoto T (1988) One-month injectable microcapsules of luteinizing hormone-releasing hormone agonist (leuprolide acetate) for treating experimental endometriosis in rats. J Pharmacol and Experiment Therap 244: 744-750.

14. Ogawa Y, Okada H, Heya T, Shimamoto T (1989) Controlled release of LHRH agonist, leuprolide acetate, from microcapsules: Serum drug level profiles and pharmacological effects in animals. $J$ Pharm Pharmacol 41: 439-444.

15. Sudo K, Masaki T, Yoshida K. Fujita T (1990) Changes and recovery of endocrine functions in female rats after treatment of TAP-144-SR, a sustained-release formulation of a potent LH-RH agonist. Japanese Pharmacology छ Therapeutics (Yakuri to Chiryou) 18: Suppl. 3: 11-18 (In Japanese).

16. Sudo K, Yamazaki I, Masuoka M, Nakayama R (1979) Effects of the anti-androgen TSAA-291 (16 $\beta$-ethyl-17 $\beta$-hydroxy-4-oestren-3-one) on the secretion of gonadotropins. Acta Endocrinol (Copenh) 92: Suppl. 229: 53-66.

17. Greenwood FC, Hunter WM, Clover JS (1963) The preparation of ${ }^{131}$ I-labelled human growth hormone of high specific radioactivity. Biochem $J 89$ : $114-123$. 
18. Sakura Y, Masaki T, Sudo K, Nomura M, Shino A (1990) Histological studies on the therapeutic effect of sustained-release microspheres of a potent LHRH agonist (leuprorelin acetate) in an experimental endometriosis model in rats. Endocrinol Japon 37: 719-729.
19. Sudo K, Masaki T, Shiota K, Kawase M, Fujita T (1990) Endocrinological studies on TAP-144-SR, a sustained-release formulation of a potent $\mathrm{GnRH}$ agonist (D-Leu ${ }^{6}-\left[\right.$ des-Gly $\left.{ }^{10}-\mathrm{NH}_{2}\right]-\mathrm{GnRH}$ ethylamide), in male rats. Endocrinol Japon 37: 685-693. 